\title{
Assessment of metal-assisted nucleophile activation in the hepatitis delta virus ribozyme from molecular simulation and 3D-RISM
}

\author{
BRIAN K. RADAK, ${ }^{1,2}$ TAI-SUNG LEE, ${ }^{1}$ MICHAEL E. HARRIS, ${ }^{3}$ and DARRIN M. YORK ${ }^{1}$ \\ ${ }^{1}$ Center for Integrative Proteomics Research and Department of Chemistry and Chemical Biology, Rutgers University, Piscataway, New Jersey \\ 08854-8076, USA \\ ${ }^{2}$ Department of Chemistry, University of Minnesota, Minneapolis, Minnesota 55455-0431, USA \\ ${ }^{3}$ Department of Biochemistry, Case Western Reserve University School of Medicine, Cleveland, Ohio 44106, USA
}

\begin{abstract}
The hepatitis delta virus ribozyme is an efficient catalyst of RNA $2^{\prime}$-O-transphosphorylation and has emerged as a key experimental system for identifying and characterizing fundamental features of RNA catalysis. Recent structural and biochemical data have led to a proposed mechanistic model whereby an active site $\mathrm{Mg}^{2+}$ ion facilitates deprotonation of the $\mathrm{O2}^{\prime}$ nucleophile, and a protonated cytosine residue $(\mathrm{C} 75)$ acts as an acid to donate a proton to the O5' leaving group as noted in a previous study. This model assumes that the active site $\mathrm{Mg}^{2+}$ ion forms an inner-sphere coordination with the $\mathrm{O2}^{\prime}$ nucleophile and a nonbridging oxygen of the scissile phosphate. These contacts, however, are not fully resolved in the crystal structure, and biochemical data are not able to unambiguously exclude other mechanistic models. In order to explore the feasibility of this model, we exhaustively mapped the free energy surfaces with different active site ion occupancies via quantum mechanical/ molecular mechanical (QM/MM) simulations. We further incorporate a three-dimensional reference interaction site model for the solvated ion atmosphere that allows these calculations to consider not only the rate associated with the chemical steps, but also the probability of observing the system in the presumed active state with the $\mathrm{Mg}^{2+}$ ion bound. The $\mathrm{QM} / \mathrm{MM}$ results predict that a pathway involving metal-assisted nucleophile activation is feasible based on the rate-controlling transition state barrier departing from the presumed metal-bound active state. However, QM/MM results for a similar pathway in the absence of $\mathrm{Mg}^{2+}$ are not consistent with experimental data, suggesting that a structural model in which the crystallographically determined $\mathrm{Mg}^{2+}$ is simply replaced with $\mathrm{Na}^{+}$is likely incorrect. It should be emphasized, however, that these results hinge upon the assumption of the validity of the presumed $\mathrm{Mg}^{2+}$-bound starting state, which has not yet been definitively verified experimentally, nor explored in depth computationally. Thus, further experimental and theoretical study is needed such that a consensus view of the catalytic mechanism emerges.
\end{abstract}

Keywords: QM/MM; 3D-RISM; RNA catalysis; mechanism; free energy

\section{INTRODUCTION}

The hepatitis delta virus ribozyme (HDVr) is a small, selfcleaving ribozyme found in the genome of a satellite of the hepatitis B virus (Kuo et al. 1988; Sharmeen et al. 1988). Of the few known viral ribozymes, it is the only one found in an animal virus (Lai 1995) and is of particular interest due to the existence of similar sequences in both the human genome (Salehi-Ashtiani et al. 2006) and the genome of many other eukaryotes (Webb et al. 2009; Webb and Lupták 2011). It is now generally accepted that ribozymes like the HDVr use a variety of catalytic strategies, including site-specific shifts of nucleobase $\mathrm{p} K_{\mathrm{a}}$ 's and/or recruitment of divalent metal ions

Corresponding author: Darrin.York@rutgers.edu

Article published online ahead of print. Article and publication date are at http://www.rnajournal.org/cgi/doi/10.1261/rna.051466.115. Freely available online through the RNA Open Access option. to stabilize electrostatically strained structures (Fedor 2009; Schnabl and Sigel 2010; Wong and Pollack 2010; Golden et al. 2013; Ward et al. 2014; Panteva et al. 2015). These motifs are well established from detailed experimental and theoretical analysis of the hairpin and hammerhead ribozymes (Lee et al. 2007, 2009; Leclerc 2010; Suydam et al. 2010; Cottrell et al. 2011; Kath-Schorr et al. 2012).

Indeed, experimental studies of the HDVr have identified a specific cytosine residue, C75, as being critical for catalysis (Thill et al. 1993; Ferré-D'Amaré et al. 1998; Perrotta et al. 1999; Nakano et al. 2000; Shih and Been 2001) and a broad range of evidence supports a scenario in which the $\mathrm{p} K_{\mathrm{a}}$ of C75 is shifted $\sim 2$ units toward neutrality compared to both a single nucleotide in solution (Gong et al. 2007) and

(C) 2015 Radak et al. This article, published in RNA, is available under a Creative Commons License (Attribution 4.0 International), as described at http://creativecommons.org/licenses/by/4.0/. 
the cleaved product state (Lupták et al. 2001). Furthermore, biochemical data support the supposition that this residue donates a proton to the leaving group, thus acting as an acid catalyst (Das and Piccirilli 2005; Perrotta et al. 2006).

In addition to their role in RNA folding, metal ions also contribute to HDVr catalysis. The HDVr requires millimolar concentrations of $\mathrm{Mg}^{2+}$ ions (Wu et al. 1989; Rosenstein and Been 1990; Been et al. 1992)—or some other divalent ion (Suh et al. 1993) — in order to reach an optimal reaction rate under near-physiological conditions. Detailed biochemical and kinetic studies have revealed multiple functional divalent metal binding sites and demonstrated that molar concentrations of monovalent ions alone can support catalysis (Nakano et al. 2001, 2003; Perrotta and Been 2006). Sitebound metal ion interactions have been identified and characterized via crystallography (Ke et al. 2004, 2007; Chen et al. 2010), spectroscopy (Gong et al. 2009), chemical probing experiments (Chen et al. 2009, 2013; Lévesque et al. 2012; Thaplyal et al. 2015), and molecular simulation (Lee et al. 2011; Veeraraghavan et al. 2011a,b; Chen et al. 2013). Moreover, $\mathrm{pH}$-rate profiles for the reaction in the absence of $\mathrm{Mg}^{2+}$ and for mutants designed to disrupt binding of the proposed active site ion are inverted relative to the reaction of the native $\mathrm{HDVr}$ in $\mathrm{Mg}^{2+}$ (Perrotta and Been 2006; Chen et al. 2013). Phosphorothioate interference studies have revealed sites of potential site-bound metal ion interactions via coordination to one or more nonbridging oxygens, including the pro- $\mathrm{R}_{\mathrm{P}}$ position of the scissile phosphate (Jeoung et al. 1994; Fauzi et al. 1997; Prabhu et al. 1997; Raines and Gottlieb 1998; Oyelere et al. 2002; Das and Piccirilli 2005; Perrotta and Been 2006; Thaplyal et al. 2013). Thiophilic metal ion rescue experiments have been interpreted as supporting a catalytic metal ion interacting with this position. However, unlike typical results for other metalloribozymes (Frederiksen and Piccirilli 2009), the metal rescue is unconventional in that the substitution decreases the susceptibility of the ribozyme to inhibition by thiophilic metal ions rather than being activated by their presence (Thaplyal et al. 2013). Recent studies of stereospecific thio effects over a wide range of ionic conditions reveal inverse thio effects at the pro- $S_{\mathrm{P}}$ position with large monovalent and divalent ions (Thaplyal et al. 2015). These results, taken together with $\mathrm{pH}$-rate profiles, proton inventories, ammonium/imidazole rescue experiments, and computational simulations, have been interpreted to suggest that the HDVr mechanism can shift from a concerted metal ion-stabilized to a stepwise proton transfer-stabilized pathway with decreasing metal ion charge density (Thaplyal et al.2015). Clearly the evidence reactive $\mathrm{O} 2^{\prime}$ oxyanion. for the participation of an active site metal is very strong, but the details of its interactions in the transition state and its role in catalysis are not yet clear.

Computational simulation allows for direct exploration of specific mechanistic pathways of ribozymes as well as identification of experimental observables that can potentially be used to discriminate between them (Panteva et al. 2015). In the case of the HDVr, molecular simulations can be used to specifically position $\mathrm{Mg}^{2+}$ at locations thought to facilitate catalysis. The results of these simulations can then be used to evaluate: (1) the thermodynamics of ion association, (2) the catalytic competency of the resulting configurations, and (3) the structural and dynamical characteristics of mechanistic pathways and how they might affect experimental observables.

Recent quantum mechanical/molecular mechanical (QM/ MM) studies, both via adiabatic calculations (Ganguly et al. 2011) and the string method (Ganguly et al. 2014; Thaplyal et al. 2015), have focused primarily on analyzing the details of a specific set of active site metal interactions proposed by Chen et al. (2010) and Golden (2011) (Fig. 1). This mechanistic model was inferred from both crystallographic data and structural modeling via homology with the hammerhead ribozyme and is consistent with much of the available biochemical data (Golden 2011). The calculations have provided a detailed catalytic pathway partially consistent with experimental data as well as some specific mechanistic predictions. These simulations predicted a change from a concerted mechanism when the active site $\mathrm{Mg}^{2+}$ is present to a stepwise pathway (via a protonated phosphorane intermediate) in the presence of $\mathrm{Na}^{+}$and absence of $\mathrm{Mg}^{2+}$ (Ganguly et al. 2014).

The work presented here provides a detailed computational perspective on active site $\mathrm{Mg}^{2+}$ association and its contribution to catalysis. This is done by examining the distribution of states connecting divalent metal ion binding and
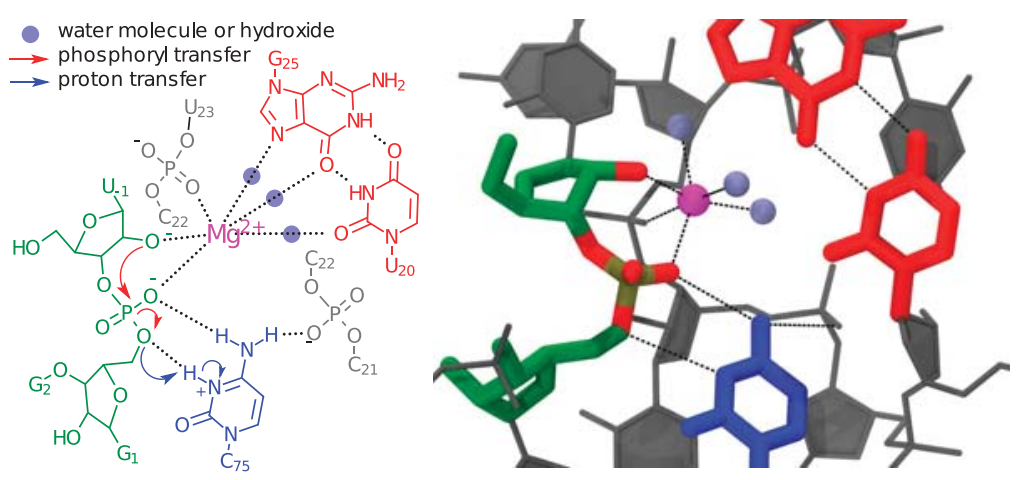

FIGURE 1. Schematic diagram of the catalytic mechanism proposed by Chen et al. (2010) and Golden (2011). Biochemical, structural, and computational data together indicate that a protonated cytosine residue (blue) acts as an acid to transfer a proton to the $\mathrm{O5}^{\prime}$ leaving group (blue arrows). Notably, the model shows that a hexacoordinated $\mathrm{Mg}^{2+}$ ion (magenta) with three water mediated contacts (gray spheres) to a GU reverse wobble (red) as well as a hydrogen bond between cytosine and the scissile phosphate aid in organizing the active site. The three remaining $\mathrm{Mg}^{2+}$ ligands are phosphate oxygens, including the $\mathrm{O}^{\prime}$ nucleophile. This interaction is proposed to play a role in activating the nucleophile by lowering its $\mathrm{p} K_{\mathrm{a}}$ to favor the formation of the more 
nucleophile activation within a thermodynamic framework based on a molecular mechanics/three-dimensional reference interaction site model (MM/3D-RISM). The states predicted to be catalytically competent are then examined with QM/MM simulations. An overarching theme in this work is that, in order to draw direct comparison with experimental kinetic data, one must consider not only the rate associated with the chemical steps of the reaction departing from a presumed active state with a $\mathrm{Mg}^{2+}$ bound in the active site, but also the probability of observing the system in that active state. The QM/MM results suggest that, under the assumption of the validity of the metal ion binding mode described above, a pathway involving metal-assisted nucleophile activation is feasible with a rate constant in reasonable agreement with experiment. However, QM/MM results for a similar pathway in the absence of $\mathrm{Mg}^{2+}$ are not in agreement with experiment, suggesting that the structural model in the absence of $\mathrm{Mg}^{2+}$ is likely incorrect or, at the very least, incomplete. Further, there remain questions regarding the interpretation of other experimental biochemical data within this mechanistic scenario. These include possible conformational switching of a wobble pair associated with $\mathrm{Mg}^{2+}$ binding (Lévesque et al. 2012; Chen et al. 2013), mutational effects that should be related to $\mathrm{Mg}^{2+}$ binding but are outside of the proposed active site (Chen et al. 2009; Gong et al. 2009), and anti-correlation of $\mathrm{Mg}^{2+}$ binding and the observed $\mathrm{p} K_{\mathrm{a}}$ shift in C75 (Gong et al. 2007).

\section{RESULTS}

\section{Simulations of the HDVr in different precatalytic states}

Multiple HDVr states ( $\mathrm{RH}, \mathrm{R}^{-}, \mathrm{RH}: \mathrm{Mg}^{2+}$, and $\mathrm{R}^{-}: \mathrm{Mg}^{2+}$ ) were defined based on the protonation state of $\mathrm{U}-1: \mathrm{O} 2^{\prime}$ and whether or not $\mathrm{Mg}^{2+}$ was specifically bound as in the crystallographic model (see Figs. 1, 2; Chen et al. 2010; Golden 2011). As a baseline exploration of the conformational space available to each state, long-time MD trajectories were propagated for at least $100 \mathrm{nsec}$ of data collection. In all states, the trajectories displayed remarkable stability in an active, inline conformation of the U-1:O2' nucleophile. This was true regardless of whether or not a crystallographically resolved $\mathrm{Mg}^{2+}$ ion was artificially ejected from the active site (by swapping coordinates with a bulk $\mathrm{Na}^{+}$ion, as in the $\mathrm{RH}$ and $\mathrm{R}^{-}$ states) or the nucleophile was protonated or deprotonated (as in the $\mathrm{R}^{-}$and $\mathrm{R}^{-}: \mathrm{Mg}^{2+}$ states). In order to evaluate these conformational searches, cluster analysis was performed and yielded single dominant clusters ( $>80 \%$ occupancy) with small fluctuations of the active site heavy atoms, although this was less true in the case of a deprotonated nucleophile.

\section{Solvation analysis with 3D-RISM and NLPB-SA}

The ultimate goal of MM/NLPB-SA and MM/3D-RISM type calculations is to assess energetics and solvation effects; how-

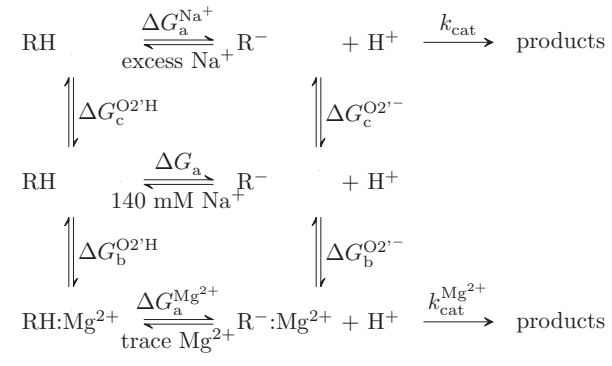

FIGURE 2. Reaction scheme for (de)protonation of the HDVr at U-1: $\mathrm{O} 2^{\prime}$ and $\mathrm{Mg}^{2+}$ binding events needed to attain catalytically active states with and without $\mathrm{Mg}^{2+}\left(k_{\mathrm{cat}}^{\mathrm{Mg} 2+}\right.$ and $k_{\text {cat }}$, respectively). $\mathrm{RH}$ indicates a (neutral) protonated reactant state $\left(\mathrm{O}^{\prime} \mathrm{H}\right)$, while $\mathrm{R}^{-}$indicates a deprotonated reactant state $\left(\mathrm{O}^{\prime-}\right)$. In all cases, $\mathrm{C} 75$ is assumed to be in a protonated state.

ever, these methods make significantly different assumptions concerning the structure of the solvent environment (e.g., standard NLPB neglects solvent-solvent correlations, whereas 3D-RISM does not). Thus, as an initial test of the quality of 3D-RISM and NLPB calculations, the $\mathrm{HDVr}-\mathrm{Na}^{+}$pair distribution functions (PDFs) were calculated on a structure from a trajectory in which a $\mathrm{Mg}^{2+}$ ion was not bound (Fig. 3). These PDFs describe, in an average sense, the three-dimensional distribution of $\mathrm{Na}^{+}$ions around the HDVr solute without the effects of bound $\mathrm{Mg}^{2+}$. The ion density distribution predicted by 3D-RISM-PSE3 matches closely that from MD simulation which places a specific, buried $\mathrm{Na}^{+}$ion near the nucleophile (Fig. 3). NLPB, on the other hand, does not predict this density or even qualitatively agree with either the 3DRISM or MD simulation ion density.

As a next step, relative free energies were derived from a thermodynamic cycle (Fig. 2) describing protonation $\left(\Delta G_{\mathrm{a}}\right)$ and binding of $\mathrm{Mg}^{2+}$ at $\mathrm{U}-1: \mathrm{O}^{\prime}\left(\Delta G_{\mathrm{b}}\right)$, as well as changes in the background concentration of $\mathrm{Na}^{+}\left(\Delta G_{\mathrm{c}}\right)$. From these definitions, $\mathrm{p} K_{\mathrm{a}}$ shifts for deprotonation of the $\mathrm{U}-1: \mathrm{O}^{\prime}$ nucleophile, $\Delta \mathrm{p} K_{\mathrm{a}}$, can be defined in proportion to the difference in the free energies of deprotonation or, alternatively, the free energies of binding or change in ionic strength.

$$
\begin{aligned}
\Delta \Delta G_{\mathrm{a}}^{x} & \equiv \Delta G_{\mathrm{a}}^{x}-\Delta G_{\mathrm{a}}=\Delta G_{\mathrm{b}}^{\mathrm{O} 2^{\prime}-}-\Delta G_{\mathrm{b}}^{\mathrm{O} 2^{\prime} \mathrm{H}} \\
& =\Delta G_{\mathrm{c}}^{\mathrm{O} 2^{\prime}-}-\Delta G_{\mathrm{c}}^{\mathrm{O} 2^{\prime} \mathrm{H}} \\
& \Delta \mathrm{pK}_{\mathrm{a}}^{x}=\frac{\Delta \Delta G_{\mathrm{a}}^{x}}{R T \ln 10} \\
x & =\mathrm{Mg}^{2+} \text { or } \mathrm{Na}^{+} .
\end{aligned}
$$

As shown in Table 2 (below), 3D-RISM calculations with the $\mathrm{KH}$ and PSE2 closures yield $\mathrm{p} K_{\mathrm{a}}$ shifts of $\sim 4$ units in the presence of $\mathrm{Mg}^{2+}$ (assumed to be explicitly bound with a $20 \mathrm{mM}$ background) but only $\sim 2.5$ units in the presence of $\mathrm{Na}^{+}$(i.e., with $1 \mathrm{M}$ background). The use of other repulsive-dispersive models for $\mathrm{Mg}^{2+}$, for both the solute and/or solvent, did not change the results by more than a few $\mathrm{kcal} /$ 


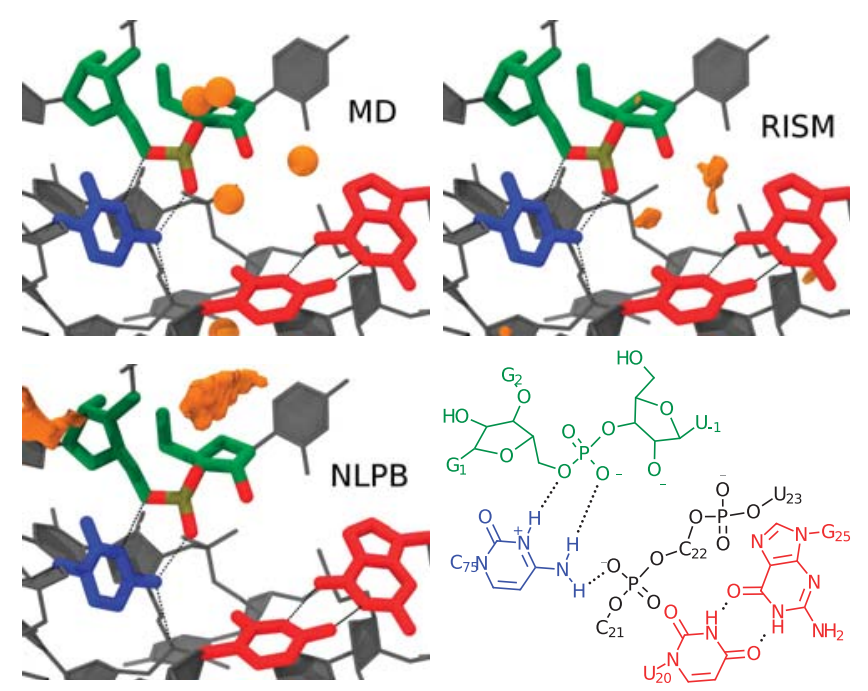

FIGURE 3. $\mathrm{Na}^{+}$pair distribution functions (orange isosurfaces) computed via NLPB (bottom left) and 3D-RISM-PSE3 (top right) compared with peak positions (orange spheres) from MD and volmap (top left). Isosurfaces correspond to a concentration of 300 times the bulk (140 $\mathrm{mM}$ ). Density beyond $3 \AA$ from the active site residues was clipped for clarity.

mol and never increased the magnitude of the $\mathrm{p} K_{\mathrm{a}}$ shifts significantly beyond the reported values. Similar parameter insensitivities were observed when changing background salt concentrations (e.g., $10 \mathrm{mM} \mathrm{Mg}{ }^{2+}$ ). Results for NLPB-SA displayed a trend similar to 3D-RISM, but with a much more dramatic shift in the presence of $\mathrm{Mg}^{2+}$ (57 units) and a shift of $<1$ unit in the presence of $\mathrm{Na}^{+}$. These results were essentially unchanged by omitting surface area terms.

Lastly, the relative free energies of the two different ionic ground states ( $\mathrm{RH}$ and $\mathrm{RH}: \mathrm{Mg}^{2+}$ ) can be determined as the difference in the relative free energies of deprotonation $\left(\Delta G_{\mathrm{a}}^{\mathrm{Mg} 2+}-\Delta G_{\mathrm{a}}^{\mathrm{Na}+}\right.$ in Table 2, below). Again, both RISM closures predict similar shifts of $\sim 2 \mathrm{kcal} / \mathrm{mol}$ in favor of the $\mathrm{Mg}^{2+}$ bound state. Also as above, NLPB-SA predicts a much larger shift $(77.2 \mathrm{kcal} / \mathrm{mol})$.

\section{QM/MM free energy surfaces}

QM/MM free energy surfaces of the HDVr catalyzed reaction were calculated both with $\left(\mathrm{R}^{-}: \mathrm{Mg}^{2+}\right)$ and without $\left(\mathrm{R}^{-}\right) \mathrm{Mg}^{2+}$ present in the active site (Fig. 2). Figure 4 shows the free energy surfaces defined by axes corresponding to phosphoryl transfer $\left(\xi_{\text {PhoT }}\right)$ and general acid proton transfer from C75 $\left(\xi_{\mathrm{ProT}}^{\mathrm{GA}}\right)$. The results are largely indistinguishable, with only small differences in the location of their stationary points (Fig. 4). The shapes of the reactant and product basins are also quite similar with nearly identical eigenvalues (Table 1). This analysis can be extended further by quantifying the reaction coordinate motions in each basin. To this end, the extent of coupling between the normal mode motions was analyzed by comparing the normal mode basis to the phosphoryl/proton transfer basis. We consider the modes to be completely coupled if the phosphoryl/proton transfer component magnitudes are equal (i.e., the normal mode basis is rotated $45^{\circ}$ with respect to the axes). This coupling can be expressed on a scale of $0-1$ by calculating the absolute value of the cosine of the angle of rotation (Table 1). For both free energy surfaces the normal modes indicate significant decoupling of phosphoryl and proton transfer in the product states. In the reactant states, however, there is stronger coupling, with slow oscillation primarily along the proton transfer coordinate. The (reactive) mode orthogonal to this describes mostly high frequency phosphoryl transfer motion. The transition states are likewise indicative of strongly coupled motions, indicating that motion along the general acid coordinate increases as the reaction progresses.

Analysis of the relative free energies of the stationary points can be simplified by projecting the minimum free energy paths of each surface onto a sum of atom transfer coordinates, $\xi_{\mathrm{PhoT}}+\xi_{\mathrm{ProT}}^{\mathrm{GA}}$ (see Materials and Methods). This leads to a simple, univariate function of the relative free energy linking the (activated) reactant and product states (Fig. 5, bottom). Calculating these paths with either the MBAR or vFEP method gave indistinguishable results within statistical error. Although the energy differences between the reactant and transition states (neglecting Jacobian corrections) are quite different with and without $\mathrm{Mg}^{2+}$ (18.0 and $10.0 \mathrm{kcal} /$ mol, respectively), several relevant average bond lengths are nearly identical along both paths (Fig. 5, top). The only significant exception is the average length of the $\mathrm{U}-1: \mathrm{O5}^{\prime}$ to G1:P bond (Fig. 5, top, red lines). Regardless, in both cases the start of the reaction is dominated by formation of the $\mathrm{P}-\mathrm{O} 2$ ' bond (Fig. 5, top, green lines) with an increasingly strong hydrogen bond between G1:O5' and C75:N3 as the transition state is crossed. This hydrogen bond concertedly changes to proton transfer as the $\mathrm{P}-\mathrm{O}^{\prime}$ bond breaks (Fig. 5 , top, red and magenta lines). However, the covalent bond between the proton and its donor, C75:N3, does not appear to break until the reaction has progressed considerably (Fig. 5 , top, blue lines). In fact, this bond does not appear to form at all significantly until P-O5' bond breakage has nearly completed. This is similar to the observation that the normal modes display an increasing amount of coupling between the phosphoryl and proton transfer coordinates as the reaction progresses toward the transition state.

\section{DISCUSSION}

The main purpose of the present work is to evaluate mechanistic scenarios departing from the suggested metal ion binding mode previously proposed in the literature (Chen et al. 2010; Golden 2011) by establishing the experimentally testable consequences and identifying key aspects deserving further consideration. The computational results reported here accomplish this goal by integrating several approaches aimed at different time and length scales (i.e., fast chemical events 


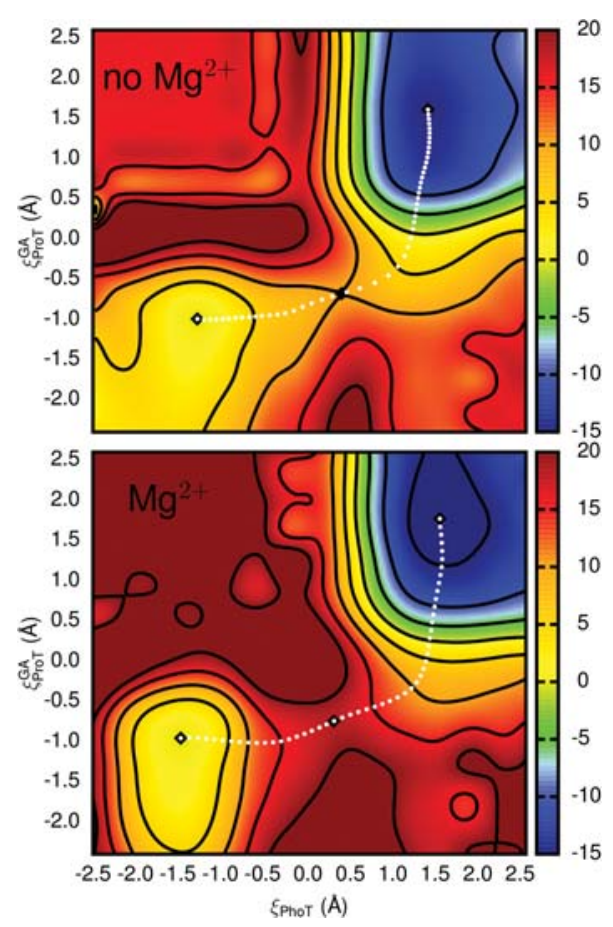

FIGURE 4. Free energy surfaces of the HDVr catalytic reaction starting from an activated (post-base) state with (bottom) and without (top) $\mathrm{Mg}^{2+}$ bound at the position hypothesized by Chen et al. (2010). Axis and abscissa correspond to atom transfer coordinates for general acid proton transfer and phosphoryl transfer ( $\xi_{\mathrm{ProT}}^{\mathrm{GA}}$ and $\xi_{\mathrm{PhoT}}$, respectively). Free energies are in $\mathrm{kcal} / \mathrm{mol}$ relative to the reactant minima with $5 \mathrm{kcal} /$ mol separation of contour lines. Minima and saddle points (black diamonds) and a minimum free energy path (white dots) are also shown.

via $\mathrm{QM} / \mathrm{MM} \mathrm{MD}$ and slower/longer length RNA motions via MM MD) as well as solvent considerations (i.e., explicit MD and 3D-RISM). The resulting new information can be used to evaluate the specific atomistic reaction pathways and allows structural/energetic analysis of the related ground states within a simple equilibrium scheme that relates ionic interactions and deprotonation of the $\mathrm{O} 2^{\prime}$ nucleophile (Fig. 2).

\section{Comparison with nonenzymatic reactions}

Enzymatic reactions are often best characterized by their relation to "uncatalyzed" (i.e., nonenzymatic) reactions. Calculations for several reaction models of nonenzymatic RNA cleavage were recently reported and are consistent with the computational approach used here (Radak et al. 2013a). The key difference between the enzymatic and nonenzymatic reactions is the absence of the enzymatic scaffolding (which organizes the active site) as well as the absence of a general acid (or any kind of leaving group stabilization). The nonenzymatic reaction (in this case, specific base catalyzed cleavage of an abasic dinucleotide) was also studied from a ground state containing a deprotonated nucleophile and thus is representative of the intrinsic reaction barrier and uncoupled from $\mathrm{pH}$ considerations.
The free energy profile of the nonenzymatic reaction is compared with those of the two HDVr catalyzed reactions (i.e., with and without $\mathrm{Mg}^{2+}$ ) in the lower part of Figure 5. Both HDVr catalyzed reactions have distinctly lower catalytic barriers and the reaction in the absence of $\mathrm{Mg}^{2+}$ is less than half that of the nonenzymatic reaction (10.0 versus $\sim 21$ $\mathrm{kcal} / \mathrm{mol}$ ). This reduction in the barrier can be reasonably attributed to the structural and proton transfer effects already mentioned. First, the HDVr environment structurally orients the activated nucleophile in a position much closer to the scissile phosphate. Indeed, Figure 5 (top, green lines) shows that the nucleophile to phosphorous distance $\left(r_{\mathrm{P}-\mathrm{O} 2^{\prime}}\right)$ is $\sim 1 \AA$ shorter in the reactant state of the HDVr (both metal scenarios) than for an RNA dinucleotide in solution. Moving along the free energy profile for the nonenzymatic reaction up to a distance more in line with the HDVr suggests a catalytic effect of $4-5 \mathrm{kcal} / \mathrm{mol}$ from this structural alignment alone $\left(\xi_{\text {PhoT }}+\xi_{\text {ProT }}^{\mathrm{GA}} \approx-1.1 \AA\right.$, Fig. 5 , bottom). Second, in the HDVr the protonated C75 donates two hydrogen bonds to the scissile phosphate and one of these bonds changes to a proton transfer as the reaction proceeds. An ad hoc bookkeeping of these interactions might suggest $\approx 2-3 \mathrm{kcal} / \mathrm{mol}$ per hydrogen bond. Along with other general electrostatic stabilization, the $\sim 11 \mathrm{kcal} / \mathrm{mol}$ difference between the enzymatic (without $\mathrm{Mg}^{2+}$ ) and nonenzymatic reactions can thus be reasonably accounted for.

\section{HDVr ground states}

In estimating relative activation energies from the QM/MM free energy surfaces calculated here for the HDVr reaction, two major factors must be properly considered. First, the HDVr activated states $\left(\mathrm{R}^{-}\right.$and $\left.\mathrm{R}^{-}: \mathrm{Mg}^{2+}\right)$ are not identical, as they correspond to two very different ionic bound states. Second, the ground states in these simulations are assumed to be preactivated by equilibrium deprotonation of the $\mathrm{O} 2^{\prime}$ nucleophile (see Fig. 2). For the enzymatic reaction at neutral or similar $\mathrm{pH}$, however, the $\mathrm{O}_{2}^{\prime}$ is protonated in the ground state; deprotonation of the nucleophile is assumed to be an equilibrium process (specific base catalysis) that governs the population of the activated reactant state. Decreasing the population of the deprotonated $\mathrm{O}_{2}^{\prime}$ state in turn decreases the concentration of active ribozyme and therefore attenuates the intrinsic rate constant down to the experimentally observed value (e.g., the log-linear behavior observed in some $\mathrm{pH}$-rate profiles). The population of active HDVr will depend on the correct protonation of both the $\mathrm{O} 2^{\prime}$ and $\mathrm{C} 75$.

Raman crystallographic measurements have indicated that the $\mathrm{p} K_{\mathrm{a}}$ of $\mathrm{C} 75$ may be anti-correlated with a $\mathrm{Mg}^{2+}$ binding event. However, it is possible that it is anti-correlated with a different binding site than the one investigated here (Gong et al. 2007; Chen et al. 2009). Additionally, at pH values below the $\mathrm{p} K_{\mathrm{a}}$ of C75 ( $\left.\sim 6\right)$, this residue will be predominantly in its active form. As such, we proceed under the assumption that C75 is protonated in all states considered 
TABLE 1. Stationary point analysis of free energy profiles for the HDVr catalytic reaction

\begin{tabular}{|c|c|c|c|c|c|c|}
\hline & \multicolumn{3}{|c|}{$\Delta G$} & \multirow{2}{*}{$\frac{\mathrm{RC}}{\text { Coupling }}$} & \multirow[b]{2}{*}{$v_{1}$} & \multirow[b]{2}{*}{$v_{2}$} \\
\hline & Expt. & $\mathrm{DFT}^{\mathrm{d}}$ & FEP/corr. & & & \\
\hline \multicolumn{7}{|l|}{ Reactant state } \\
\hline $\mathrm{Mg}^{2+}$ & - & - & - & 0.34 & 3.7 & 15.4 \\
\hline $\mathrm{No} \mathrm{Mg}^{2+}$ & - & - & - & 0.38 & 3.8 & 15.6 \\
\hline \multicolumn{7}{|c|}{ Transition state } \\
\hline $\mathrm{Mg}^{2+}$ & $19.6^{\mathrm{a}}$ & 13 & 18.0 & 0.91 & $4.4 i$ & 17.9 \\
\hline $\mathrm{No} \mathrm{Mg}^{2+}$ & $26.8^{b} / 24.2^{c}$ & $2-4$ & $10.0 / 12.1$ & 0.96 & $3.8 i$ & 22.4 \\
\hline \multicolumn{7}{|l|}{ Product state } \\
\hline $\mathrm{Mg}^{2+}$ & - & $\sim-6^{\mathrm{e}}$ & -16.9 & 0.02 & 3.3 & 10.6 \\
\hline $\mathrm{No} \mathrm{Mg}^{2+}$ & - & $\sim-25^{\mathrm{e}}$ & -14.6 & 0.11 & 3.3 & 11.0 \\
\hline
\end{tabular}

${ }^{\mathrm{a}} U$ sing $k_{\max }$ at $310 \mathrm{~K}, \mathrm{pH} 7.0$ from Chen et al. (2013).

${ }^{b} U$ sing $k_{\text {obs }}$ at $310 \mathrm{~K}, \mathrm{pH} 6.0,1 \mathrm{M} \mathrm{NaCl}$ from Thaplyal et al. (2013).

${ }^{\mathrm{C}} U \operatorname{sing} k_{\text {obs }}$ at $310 \mathrm{~K}, \mathrm{pH} \mathrm{6.1,4} \mathrm{M} \mathrm{NaCl}$ and a genomic construct from Perrotta and Been (2006).

dUsing string method with B3LYP/6-31G** from Ganguly et al. (2014).

${ }^{\mathrm{e}}$ Not reported, estimated visually from graph.

Analysis of free energy profiles (FEPs) of the HDVr catalytic reaction (Fig. 4) including normal mode analysis of stationary points and comparisons to previous studies. Relative free energies $(\Delta G)$ are in kilocalories per mole and frequencies $(v)$ are in $\mathrm{ps}^{-1}$. Reaction coordinate $(\mathrm{RC})$ coupling values represent a nominal measure of the amount of coupling between atom transfer modes (coupling $=|\cos \theta|$, where $\theta$ is the angle of rotation of the normal mode basis with respect to the unit vector orthogonal to the phosphoryl transfer/ proton transfer basis; $0=$ completely decoupled; $1=$ completely coupled).

\section{Comparison of metal-bound states}

Since it is well established that the HDVr is more catalytically proficient in the presence of divalent ions than monovalent ions (Nakano et al. 2001; Perrotta and Been 2006; Thaplyal et al. 2013), it is perhaps initially surprising that the predicted free energy barrier from the activated precursor in the absence of a bound $\mathrm{Mg}^{2+}$ ion $(10 \mathrm{kcal} / \mathrm{mol})$ is nearly half that when $\mathrm{Mg}^{2+}$ is bound (18 kcal/mol, see Table 1; Fig. 5). However, as described above, the reactant state on these surfaces is a "deprotonated" oxyanion and should clearly have strong, favorable electrostatic interactions with nearby cations. The negatively charged $\mathrm{O} 2^{\prime}$ nucleophile near $\mathrm{Mg}^{2+}$ is thus better stabilized by the higher concentration of proximal positive charge. This charge preferentially stabilizes the reactant state over the transition state and effectively raises the barrier. In a related observation, $\mathrm{P}-\mathrm{O} 2^{\prime}$ bond formation is quite advanced in both transition

here. In the present work, as in that of Ganguly et al. (2014), the deprotonation step is assumed to have already occurred before the reaction proceeds (i.e., during the $\mathrm{QM} / \mathrm{MM}$ simulation). Instead, preequilibrium assumptions are used to estimate the fraction of active enzyme from the relative free energies (calculated by MM/3D-RISM) of the various unreacted states (i.e., combinations of $\mathrm{Mg}^{2+}$ bound/unbound and $\mathrm{O}^{\prime}$ protonated/deprotonated). The combination of $\mathrm{QM} / \mathrm{MM}$ and MM/3D-RISM provides a feasible approach to directly calculate the relative free energy change of the deprotonation process under different ionic conditions.

The free energy estimates from 3D-RISM generally agree in trend and magnitude (Table 2). The NLPB-SA estimates, however, do not appear to be physically realistic (the predicted $\mathrm{p} K_{\mathrm{a}}$ shifts are far too large), nor do the $\mathrm{Na}^{+}$pair distribution functions match well with those obtained from MD (Fig. 3). As such, they are not considered further. The best estimate available here is from MM/3D-RISM-PSE2, as the KH closure is known to have difficulty in predicting small molecule hydration free energies (Truchon et al. 2014) as well as excess chemical potentials for simple electrolytes (Joung et al. 2013) and excess ion distributions around DNA (Giambasu et al. 2014) (although still with greater fidelity than NLPB). It is difficult to assess the exact systematic/numerical errors of these estimates, but grid spacing effects likely will not cause errors $>0.5-1 \mathrm{kcal} / \mathrm{mol}$ (Luchko et al. 2010) and systematic tests (data not shown) on the buffer size indicate errors $<0.5 \mathrm{kcal} / \mathrm{mol}$. Neglecting structural variations by clustering is probably the most substantial source of error, likely 1-2 $\mathrm{kcal} / \mathrm{mol}$. states (see Fig. 5), indicating that the negative charge is likely redistributed away from the nucleophile and toward the leaving group, giving rise to less favorable electrostatic interactions. The fact that the transition state structures with and without $\mathrm{Mg}^{2+}$ are so similar (Fig. 5, top) is sensible within a Hammond-Leffler framework since this stabilization effect should hold equally well for the charged product (note that Table 1 also shows that the "ligation" barrier is much lower in the absence of $\mathrm{Mg}^{2+}$ ). As it has been suggested that $\mathrm{Mg}^{2+}$ could act as the general base (Nakano et al. 2000), it may be worthwhile to examine the effect of replacing $\mathrm{Mg}^{2+}$ with $\mathrm{Mg}^{2+}\left(\mathrm{OH}^{-}\right)$in calculations that specifically examine the mechanism of nucleophile activation. Complementary to these calculations would be experimental studies that examine the kinetics of the general base step using a modified substrate with enhanced leaving group such as a $5^{\prime}$ thio substitution (Kath-Schorr et al. 2012) under varying ionic conditions.

In order to achieve a meaningful comparison of the reaction barriers in the presence and absence of the active site $\mathrm{Mg}^{2+}$, the ground states for these two reactions ( $\mathrm{RH}$ and $\mathrm{RH}: \mathrm{Mg}^{2+}$ ) must be thermodynamically connected. This is because the $\mathrm{QM} / \mathrm{MM}$ simulations depart from precursor states $\left(\mathrm{R}^{-}\right.$and $\left.\mathrm{R}^{-}: \mathrm{Mg}^{2+}\right)$ that assume nucleophile activation has occurred in a preequilibrium processes. This assumption is nontrivial and the probabilities of obtaining these states (and thus the required free energy) are likely quite different. The relative shift in free energy between the two reactions can clearly be related to the free energies associated with $\mathrm{O} 2$ ' deprotonation in both cases. Using the MM/3D-RISM framework described above, the best estimate of the free 


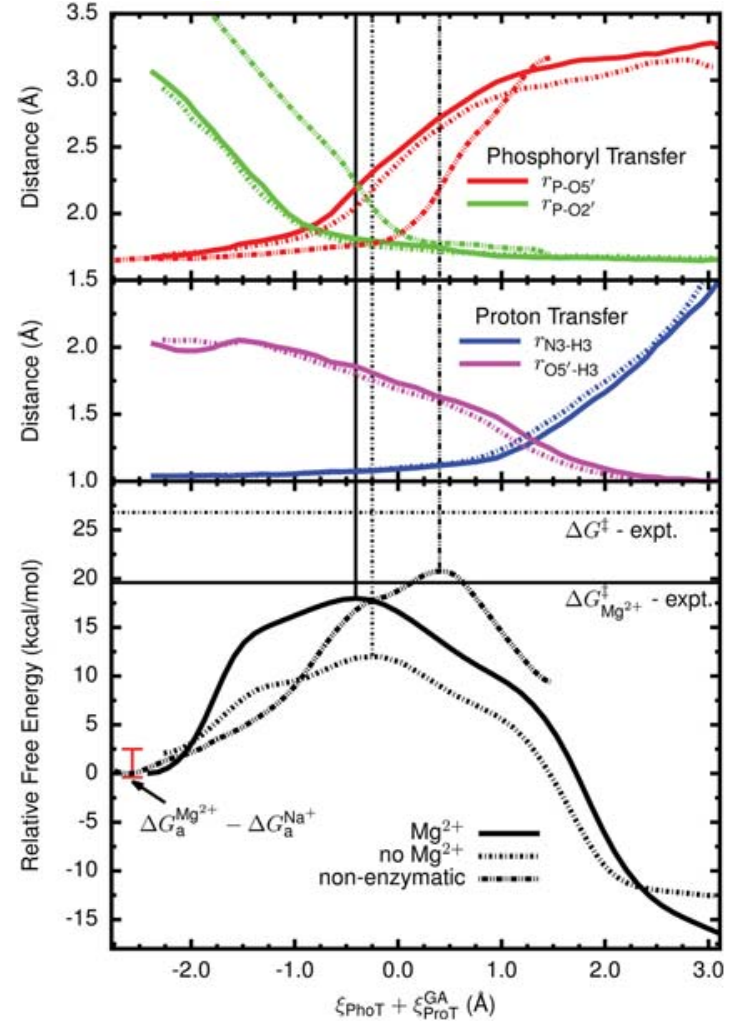

FIGURE 5. Reaction profiles (bottom) along the minimum free energy paths for the HDVr catalytic reaction starting from an activated (i.e., deprotonated) state with and without the presence of $\mathrm{Mg}^{2+}$ at the position hypothesized by Chen et al. (2010) (solid and dashed lines, respectively). The zeros of energy are set according to an estimated relative free energy of deprotonation $\left(\Delta G_{\mathrm{a}}^{\mathrm{Mg} 2+}-\Delta G_{\mathrm{a}}^{\mathrm{Na}+}=-2.1 \mathrm{kcal} / \mathrm{mol}\right)$. Averages of selected bond lengths along the path are also shown (top). The calculated (including correction) and experimental barrier heights (from classical transition state theory, in $\mathrm{kcal} / \mathrm{mol}$ ) are 18.0 and 19.6 (Chen et al. 2013) and 12.1 and 26.8 (Thaplyal et al. 2013) for the reactions with and without $\mathrm{Mg}^{2+}$, respectively.

energy shift between the two profiles is $\sim 2.1 \mathrm{kcal} / \mathrm{mol}$ in favor of the $\mathrm{Mg}^{2+}$ bound mechanism (Table 2; Fig. 5). Even with rather pessimistic error assumptions, this shift is not likely to be $>5-6 \mathrm{kcal} / \mathrm{mol}$. Clearly such a shift is qualitatively in line with experiment; however, it is far short of the experimentally expected/derived value of $\sim 16 \mathrm{kcal} / \mathrm{mol}$ (Chen et al. 2013).

A similar finding has been reported by Ganguly et al. (2014). Nevertheless, in that work, the needed free energy correction was inferred from (1) the experimental observation of a $\sim 25$-fold slower overall rate in the case of monovalent ions alone, (2) the measured $\mathrm{p} K_{\mathrm{a}}$ of the nucleophile $\mathrm{O} 2^{\prime}$ being between 1.3 and 2.7 units lower for divalent ions than for sodium ions, which can be translated as differences of between 1.8 and $3.8 \mathrm{kcal} / \mathrm{mol}$, comparable to our MM/3DRISM result ( $\sim 2.1 \mathrm{kcal} / \mathrm{mol})$, and (3) the calculated free energy barriers for the self-cleavage reaction $(\sim 13 \mathrm{kcal} / \mathrm{mol}$ and $\sim 3.5 \mathrm{kcal} / \mathrm{mol}$ for divalent and monovalent ions, respectively). As a result, the case with $\mathrm{Na}^{+}$alone is expected to be dis- favored by an additional $\sim 8$ to $10 \mathrm{kcal} / \mathrm{mol}$. Hence our study, where a theoretic correction of the free energy shift is calculated, and the study by Ganguly et al. (2014), where the needed free energy correction is inferred from experimental measurements and calculated energy barriers, both conclude that, compared with the experimental measurements, the current structural model favors the case with $\mathrm{Na}^{+}$alone by $\sim 8$ to 10 $\mathrm{kcal} / \mathrm{mol}$.

To summarize, the preceding analysis is only partially aligned with existing experimental interpretations. The reaction barrier for the HDVr with a preactivated nucleophile and site-bound $\mathrm{Mg}^{2+}$ is closely aligned with values derived from experiment, more so than previous estimates by Ganguly et al. (2014) (Table 1). Note that this agreement requires the assumption that this bound ion is present nearly $100 \%$ of the time, which is not implausible considering the low saturation point $\left(\sim 10 \mathrm{mM} \mathrm{Mg}^{2+}\right)$ of several metal titration experiments (Nakano et al. 2000, 2001; Chen et al. 2009, 2013). Combining this assertion with the $\sim 4$ unit downward $\mathrm{p} K_{\mathrm{a}}$ shift of the $\mathrm{O} 2^{\prime}$ nucleophile predicted here (in $20 \mathrm{mM}$ $\mathrm{Mg}^{2+}$ ) makes this a cohesive scenario.

However, when $\mathrm{Mg}^{2+}$ is substituted with a large $\mathrm{Na}^{+}$concentration $(1 \mathrm{M})$, the predicted variation is not as dramatic as that observed experimentally. This could be for a variety of reasons. First, the core structure obtained in the simulations, while slightly different than that obtained crystallographically, is heavily biased toward a folded state facilitated by $\mathrm{Mg}^{2+}$. The inline conformation needed for the reaction seems unaffected by the ionic environment both in our calculations and in the work by Ganguly et al. (2014). Although it has been suggested that the overall HDVr fold will not be altered when only monovalent ions are present (Ke et al. 2007), the local conformation could be altered upon charge/protonation state changes. As shown recently, the HDVr inline conformation highly correlates with the protonation state of C75 (Sripathi et al. 2014). Although a low $\mathrm{Na}^{+}$concentration $(\sim 140 \mathrm{mM})$ was able to stabilize this structure here, the present simulations cannot confirm that it is plausible for this structure to form in the complete absence of divalent metal ions in the first place. Second, the structure used here assumes constant protonation of C75. The justification here

TABLE 2. $\mathrm{p} K_{\mathrm{a}}$ shifts and relative deprotonation free energies for $\mathrm{U}-1: \mathrm{O} 2^{\prime}$ in different solvent environments

RISM-KH RISM-PSE2 NLPB-SA

\begin{tabular}{lllr}
\hline$\Delta \mathrm{p} K_{\mathrm{a}}^{\mathrm{Mg} 2+}(20 \mathrm{mM})$ & -4.1 & $-\mathbf{3 . 7}$ & -57.0 \\
$\Delta \mathrm{p} K_{\mathrm{a}}^{\mathrm{Na}+}(1 \mathrm{M})$ & -2.7 & $\mathbf{- 2 . 1}$ & -0.8 \\
$\Delta G_{\mathrm{a}}^{\mathrm{Mg} 2+}-\Delta \mathrm{G}_{\mathrm{a}}^{\mathrm{Na}+}(\mathrm{kcal} / \mathrm{mol})$ & -1.8 & $\mathbf{- 2 . 1}$ & -77.2 \\
\hline
\end{tabular}

MM/3D-RISM and MM/NLPB-SA results for U-1:O2 ${ }^{\prime} \mathrm{p} K_{\mathrm{a}}$ shifts and relative free energies under varying background salt species and concentrations. See Equation 1 and Figure 2 for definitions. A concise error analysis of these values is difficult, but an ad hoc analysis would suggest systematic errors on the order of 1-2 kcal/ mol. The numbers in bold are the best estimations (see text). 
again derives from an overall fold obtained in the presence of $\mathrm{Mg}^{2+}$. This is problematic if the $\mathrm{p} K_{\mathrm{a}}$ shift experienced by C75 is assumed to originate from the fold of the active site. In addition, both MD and 3D-RISM predict a substantially higher density of $\mathrm{Na}^{+}$(as many as three distinct sites) than $\mathrm{Mg}^{2+}$ (one to two sites) near C75 when the salt environment is changed. The overly favorable $\mathrm{p} K_{\mathrm{a}}$ shift in the presence of molar $\mathrm{Na}^{+}$predicted here may therefore be more reflective of the RNA fold rather than salt interactions. This interpretation should imply a correlation between folding due to ionic interactions and active site organization arising from protonation of $\mathrm{C} 75$, yet most experimental results indicate an "anti-correlation" of these two factors (Gong et al. 2007) (an exception to this is $\mathrm{Mg}^{2+}$ driven formation of a base triplet involving protonated C41 [Nakano and Bevilacqua 2007]). It may be possible to probe these interactions further through judicious use of inactive C75U mutants which, at the time of this writing, have been rescued by imidazole titration (Perrotta et al. 1999; Thaplyal et al. 2013) and leaving group activation (Das and Piccirilli 2005), but never in conjunction with a high monovalent salt concentration. A similar C75 $\Delta$ mutant has recently been rescued by imidazole in conjunction with ammonium ions in the absence of $\mathrm{Mg}^{2+}$ (Thaplyal et al. 2015). This suggests a more active role for $\mathrm{NH}_{4}^{+}$compared with other monovalent ions, an idea which was also probed by kinetics studies of thio substituted wild-type-like constructs (Thaplyal et al. 2015). Furthermore, a recent refitting of crystallographic data for a C75U mutant does show a fold similar to that here, but lacks both an inline attack angle for $\mathrm{U}-1: \mathrm{O} 2^{\prime}$ as well as proper alignment of the leaving group and the (missing) general acid (Kapral et al. 2014). Hence, further work is warranted in order to explore the interplay between C75 protonation, enzyme folding, and ion binding in different mutants and under different ionic conditions.

\section{Implication of the reaction pathway}

A key aspect of the mechanistic model investigated here is the high similarity between the reaction pathways with and without $\mathrm{Mg}^{2+}$ present. If these pathways are in fact similar, then a reasonable, zeroth order approximation would suggest that their heavy atom $\left({ }^{18} \mathrm{O}\right)$ kinetic isotope effect (KIE) signatures would be similar. The present calculations are not sufficiently detailed to make quantitative predictions as to what the magnitude of these effects would be. The mechanism described here, however, makes specific predictions regarding the details of transition state bonding and the qualitative impact of this on observed KIEs can be predicted. Likewise, alternative mechanisms recently described by Ganguly et al. (2014) for the $\mathrm{Mg}^{2+}$ and $\mathrm{Na}^{+}$reactions also make implicit predictions regarding the likely magnitude of isotope substitution on the reaction rate constant. A key feature of the mechanisms in both their work and ours is the asynchronicity (although to different extents) of $\mathrm{P}-\mathrm{O}^{\prime}$ bond cleavage, which lags behind
$\mathrm{P}-\mathrm{O} 2^{\prime}$ bond formation and leads to an associative transition state. Such a transition state takes the form of a phosphorane with significant charge accumulation on the nonbridging oxygens. Relevant $\mathrm{O}^{\prime}$ and $\mathrm{O}^{\prime} \mathrm{KIE}$ data would be useful evidence to interpret this transition state model. Furthermore, protonation from C75:N3 appears to occur late along the reaction coordinate. This feature is readily apparent in Figure 5 by noting the position with respect to the transition state where the lengths of the forming and cleaving bonds cross. The scenario here predicts that there would be minimal contribution to the $\mathrm{O}^{\prime} \mathrm{KIE}$ from the formation of the new $\mathrm{O}^{\prime}-\mathrm{H}$ bond. In contrast, in Ganguly et al. (2014) this point is nearly coincident with the transition state. Obviously, precise O5' KIE measurements would be able to clarify this discrepancy.

\section{Further aspects}

The present work investigated one distinct $\mathrm{Mg}^{2+}$ binding mode suggested based on crystallographic data and this mode appears to be consistent with a large amount of structural, biochemical, and computational data. However, it cannot be excluded that other binding modes may also be consistent with these data and give similar results within the present thermodynamic framework. Nonetheless, a key characteristic of the mechanism described here is that it involves multiple compensating effects due to the presence of $\mathrm{Mg}^{2+}$. The protonated ground state provides a favorable binding position which gives rise to a $\mathrm{p} K_{\mathrm{a}}$ shift of the nucleophile toward neutrality. This promotion of the activated precursor state is necessarily offset by stabilization of the reactant over the transition state, as the ion provides a +2 charge while the general acid provides only +1 . That is, in order for the system to progress toward the transition state, electrons must migrate to a region with "lower" positive charge. This penalty would of course be lower if the metal ion were absent, but then the nucleophile would be much less likely to be found in an activated state and thus the increased electrostatic barrier is unavoidable. This effect becomes obvious when the $\mathrm{Mg}^{2+}$ ion is replaced by more diffusely held $\mathrm{Na}^{+}$ ions and the barrier is lowered, but at the expense of a slightly less populated precursor state. If this reasoning is correct, then other chemical modifications to the system which lower the $\mathrm{O}^{\prime} \mathrm{p} K_{\mathrm{a}}$ should enhance the cleavage rate in low concentrations of $\mathrm{Mg}^{2+}$ or even rescue the reaction in the presence of monovalent ions alone. Such modifications might likely include the fluoromethyl substitutions made by $\mathrm{Ye}$ et al. (2007) at the $\mathrm{C} 2^{\prime}$ position of a chimeric RNA oligomer.

\section{CONCLUSION}

Molecular simulations provide a convenient and robust framework for analyzing mechanistic pathways, especially those pertaining to complex biocatalytic systems. The key strength of such methods is that they provide unambiguous atomistic detail that can be mapped to experimental 
observables. In the present work, we have performed simulations of two hypothetical reaction channels in the HDVr in order to critically assess a recently proposed mechanistic model involving a site-bound $\mathrm{Mg}^{2+}$ as well as an alternative $\mathrm{Na}^{+}$bound scenario. Once the results are properly contextualized within the required thermodynamic assumptions of metal ion binding and the resulting $\mathrm{p} K_{\mathrm{a}}$ shift of the nucleophile, they only partially agree with the experimental data, although the reasons for this appear to follow rather directly from chemical intuition. The results are consistent with a mechanistic model whereby an active site metal $\mathrm{Mg}^{2+}$ ion facilitates nucleophile activation and C75 acts as a general acid catalyst. However, the results for a highly analogous scenario involving $\mathrm{Na}^{+}$in the same role are exceedingly at odds with known experimental results. This study represents a distinct advance in that the results are integrated in a well-defined thermodynamic framework. The specific structural and dynamical details of this mechanism suggest several areas where additional experiments could probe this model further, especially the measurement of KIEs. In addition, a hitherto neglected thio substitution at U23 and chemical modification of the $\mathrm{U}-1: \mathrm{O} 2^{\prime} \mathrm{p} K_{\mathrm{a}}$ could provide evidence that would require amendment of this mechanistic model in order to maintain consistency.

\section{MATERIALS AND METHODS}

\section{Molecular dynamics}

The initial model structure coordinates (see Golden 2011) were used to generate multiple solvated topologies with roughly identical atomic compositions. These systems all included protonation at $\mathrm{C} 75$ and $\mathrm{C} 41$, the two crystallographic $\mathrm{Mg}^{2+}$ ions nearest the active site, $\sim 140 \mathrm{mM} \mathrm{NaCl}$ and enough $\mathrm{Na}^{+}$ions to neutralize the RNA net charge. For simulations in which $\mathrm{Mg}^{2+}$ was not desired to be in the active site, that ion was swapped with a bulk $\mathrm{Na}^{+}$and the system was then extensively reequilibrated.

$\mathrm{MM}$ and $\mathrm{QM} / \mathrm{MM} \mathrm{MD}$ simulations were performed using the AMBER 14 (Salomon-Ferrer et al. 2013) suite of programs. Atoms in the MM region were treated with the AMBER FF10 force field (Cornell et al. 1995; Wang et al. 2000; Pérez et al. 2007; Zgarbová et al. 2011) while those in the QM region were described by the AM1/d-PhoT semi-empirical Hamiltonian (Nam et al. 2007). The solvent environment was modeled using the TIP4P-Ew (Horn et al. 2004) rigid water model and the associated alkali metal and halide ion parameters of Joung and Cheatham (2008); magnesium was modeled based on calculations by Mayaan et al. (2004). Long-range electrostatics were treated using periodic boundary conditions and the particle mesh Ewald method (Essmann et al. 1995; Walker et al. 2008).

Long MD trajectories ( $>900 \mathrm{nsec}$ in total) were propagated from multiple initial states in which U-1:O2' was either neutral or deprotonated and $\mathrm{Mg}^{2+}$ ion was or was not specifically bound at the active site. $\mathrm{C} 75: \mathrm{N} 3$ and $\mathrm{C} 41: \mathrm{N} 3$ were always protonated, as in previous works (Lee et al. 2011; Veeraraghavan et al. 2011a,b; Chen et al. 2013). In the case in which $\mathrm{Mg}^{2+}$ was not bound, the ion was replaced with a $\mathrm{Na}^{+}$ion from the bulk and the system was reequili- brated, providing a gradual transition toward the new ion environment. Trajectories were structurally analyzed for use in 3D-RISM and nonlinear Poisson-Boltzmann-surface area (NLPB$\mathrm{SA}$ ) calculations and were also used as starting structures for QM/ MM trajectories.

\section{D-RISM and NLPB calculations}

3D-RISM and NLPB-SA calculations were performed with AMBER (Luchko et al. 2010) and its interface to the Adaptive PoissonBoltzmann Solver (APBS) (Baker et al. 2001; Konecny et al. 2012). Multiple RISM closures, including the Kovalenko-Hirata $(\mathrm{KH})$ (Kovalenko and Hirata 1999) and $n$th order partial series expansion ( $\mathrm{PSE} n, n=2,3$ ) (Kast and Kloss 2008) closures, were compared. Solvent density and solvation free energy calculations were performed on structures derived from long MD simulations by removing all solvent atoms (except bound $\mathrm{Mg}^{2+}$, when appropriate) and, when applicable, changing the charge vector to that of the deprotonated nucleophile. Relative free energies were then estimated in the usual way from the solvation free energies (Genheden et al. 2010).

The structures for 3D-RISM and NLPB-SA calculations were derived as follows. Structural analysis first was performed on MD trajectories via a hierarchical agglomerative clustering algorithm (as implemented in CPPTRAJ [Roe and Cheatham 2013]) using the mass-weighted root mean square deviation (RMSD) of heavy atoms in the active site, defined as residues $\mathrm{U}-1, \mathrm{G} 1, \mathrm{U} 20, \mathrm{C} 21, \mathrm{C} 22, \mathrm{U} 23$, C24, G25, and C75. Because the U-1 nucleobase is solvent exposed it is free to undergo syn/anti inversion which causes large changes in the RMSD while the rest of the active site remains constant. Accordingly, all nucleobase heavy atoms from U-1 were omitted from RMSD calculations. For each trajectory the cluster count (a required input parameter) was sequentially reduced from six until no more than one cluster had a fractional occupation $<1 \%$. In all cases this procedure gave rise to primary clusters with $>80 \%$ occupancy. The centroid of these clusters (i.e., the single most representative simulation snapshot by the criteria used) was then used for all free energy calculations.

RISM solvent-solvent susceptibilities were obtained via DRISM (Perkyns and Pettitt 1992) (65536 grid points, $0.0125 \AA$ spacing). The temperature and dielectric constant were set to $300 \mathrm{~K}$ and 78.4461950541166, respectively. The solvent was modeled with the cSPC/E water model (Luchko et al. 2010) and ion parameter choices consistent with the MD protocol. A constant density approximation was assumed in which the density of water sites was lowered from the net density of $55.428 \mathrm{M}\left(\approx 0.0334\right.$ molecules $\left./ \AA^{3}\right)$ as the salt concentration increased. 3D-RISM calculations used a $96 \AA$ buffer distance and no solute-solvent interaction cutoff (“-solvcut” $\gg 96$ ). The residual was solved to a tolerance of $10^{-6}$.

Because NLPB calculations are so widespread in the literature, especially on RNA systems (e.g., the work of Chen et al. [2013]; Misra and Draper [2001]; Veeraraghavan et al. [2011a]), a slightly different protocol from 3D-RISM was used in order to make our results comparable to previous NLPB studies. Following Misra and Draper (2001), dielectric constants of 80.0 and 2.0 were used for the solvent and solute interior, respectively. Solute atom radii were taken from the default mbondi set in AmberTools 14. The only exception to this were explicit $\mathrm{Mg}^{2+}$ ions, which were given a radius of $1.45 \AA$; again, see Misra and Draper (2001). Implicit $\mathrm{Na}^{+}$and $\mathrm{Cl}^{-}$ions were modeled with an exclusion radius of $2.0 \AA$. Fine grid lengths and spacings 
were chosen as close as possible to those from 3D-RISM while still satisfying the multigrid constraints imposed by APBS (Baker et al. 2001). Coarse grid lengths used the same number of grid points but twice the box length (i.e., half the fine grid resolution).

\section{QM/MM Hamiltonian replica exchange}

QM/MM Hamiltonian replica exchange umbrella sampling simulations were performed using a novel asynchronous protocol (Radak et al. 2013b) with exchanges attempted at 5-psec intervals. Sampling in each replica averaged 60-100 psec (235 nsec total). The replica states (>1300 per free energy surface) were defined by harmonic restraints, $U(\xi)$, on two atom transfer coordinates:

$$
U(\xi)=k\left(\xi-\xi_{0}\right)^{2} \xi \equiv r_{X-Y}-r_{Y-Z} .
$$

Here $r_{X-Y}$ indicates the distance between atoms $\mathrm{X}$ and $\mathrm{Y}$. For phosphoryl transfer, $\xi_{\text {PhoT }}, X=\mathrm{G} 1: 5^{\prime}, Y=\mathrm{G} 1: \mathrm{P}, Z=\mathrm{U}-1: \mathrm{O} 2^{\prime}$, and $k=50 \mathrm{kcal} / \mathrm{mol}-\AA^{2}$ and for proton transfer of the general acid, $\xi_{\text {ProT }}^{\mathrm{GA}}, X=\mathrm{G}: \mathrm{O}^{\prime}, Y=\mathrm{C} 75: \mathrm{H} 3, Z=\mathrm{C} 75: \mathrm{N} 3$, and $k=60 \mathrm{kcal} /$ mol- $\AA^{2}$ (C75:N3 is assumed to be protonated). The restraint locations, $\xi_{0}$, were never more than $0.15 \AA$ apart. The resulting data were analyzed by the multistate Bennet acceptance ratio (MBAR) (Shirts and Chodera 2008) in tandem with a Gaussian kernel density estimator (see Radak et al. 2013a for details) as well as the recently developed variational free energy profile (vFEP) method (Lee et al. 2014).

A key advantage of the variational free energy profile method is that it readily constructs smooth, differentiable free energy surfaces. It is thus straightforward to identify and assess stationary points via normal mode analysis provided that a mass can be meaningfully assigned to the relevant coordinates. In the present case the progress coordinates are taken to be atom transfer coordinates approximated as the asymmetric stretching modes of the appropriate collinear triatomic. For simplicity, the reduced masses were calculated using force constants from the AMBER force field (Cornell et al. 1995; Wang et al. 2000; Pérez et al. 2007; Zgarbová et al. 2011). Large changes in the parameters (up to $100 \%$ ) changed the masses by $<1 \%$. The mass matrix so obtained was then used to mass weight the Hessian at each stationary point and yielded the desired eigenvalues after appropriate unit conversions. The accompanying eigenvectors were then used to calculate the reaction coordinate coupling values in Table 1 by taking the absolute value of the dot product with the unit vector having a $45^{\circ}$ angle with respect to the axes.

\section{ACKNOWLEDGMENTS}

We are grateful for financial support provided by the National Institutes of Health (GM62248 to D.M.Y., GM096000 to M.E.H.) and National Science Foundation (CHE-1125332 to D.M.Y.). Computational resources were made available by the Minnesota Supercomputing Institute for Advanced Computational Research, the Extreme Science and Engineering Discovery Environment (TACC, NICS, SDSC, and PSC, TG-MCB110101 to D.M.Y.), and the National Center for Supercomputing Applications (ACI1036208 to D.M.Y.). B.K.R. also acknowledges additional computational resources from a Peter Kollman Graduate Award in Supercomputing through the American Chemical Society Division of Computers in Chemistry and NICS. We are are also grateful to Barbara Golden for sharing HDV model coordinates.

Received February 17, 2015; accepted May 26, 2015.

\section{REFERENCES}

Baker NA, Sept D, Joseph S, Holst MJ, McCammon JA. 2001. Electrostatics of nanosystems: application to microtubules and the ribosome. Proc Natl Acad Sci 98: 10037-10041.

Been MD, Perrotta AT, Rosenstein SP. 1992. Secondary structure of the self-cleaving RNA of hepatitis delta virus: applications to catalytic RNA design. Biochemistry 31: 11843-11852.

Chen J-H, Gong B, Bevilacqua PC, Carey PR, Golden BL. 2009. A catalytic metal ion interacts with the cleavage site G.U wobble in the HDV ribozyme. Biochemistry 48: 1498-1507.

Chen J-H, Yajima R, Chadalavada DM, Chase E, Bevilacqua PC, Golden BL. 2010. A $1.9 \AA$ crystal structure of the HDV ribozyme precleavage suggests both Lewis acid and general acid mechanisms contribute to phosphodiester cleavage. Biochemistry 49: 6508-6518.

Chen J, Ganguly A, Miswan Z, Hammes-Schiffer S, Bevilacqua PC, Golden BL. 2013. Identification of the catalytic $\mathrm{Mg}^{2+}$ ion in the hepatitis delta virus ribozyme. Biochemistry 52: 557-567.

Cornell WD, Cieplak P, Bayly CI, Gould IR, Kenneth M, Merz J, Ferguson DM, Spellmeyer DC, Fox T, Caldwell JW, et al. 1995. A second generation force field for the simulation of proteins, nucleic acids and organic molecules. J Am Chem Soc 117: 5179-5197.

Cottrell JW, Scott LG, Fedor MJ. 2011. The pH dependence of hairpin ribozyme catalysis reflects ionization of an active site adenine. $J$ Biol Chem 286: 17658-17664.

Das S, Piccirilli J. 2005. General acid catalysis by the hepatitis delta virus ribozyme. Nat Chem Biol 1: 45-52.

Essmann U, Perera L, Berkowitz ML, Darden T, Hsing L, Pedersen LG. 1995. A smooth particle mesh Ewald method. J Chem Phys 103: 8577-8593.

Fauzi H, Kawakami J, Nishikawa F, Nishikawa S. 1997. Analysis of the cleavage reaction of a trans-acting human hepatitis delta virus ribozyme. Nucleic Acids Res 25: 3124-3130.

Fedor MJ. 2009. Comparative enzymology and structural biology of RNA self-cleavage. Annu Rev Biophys 38: 271-299.

Ferré-D’Amaré AR, Zhou K, Doudna JA. 1998. Crystal structure of a hepatitis delta virus ribozyme. Nature 395: 567-574.

Frederiksen JK, Piccirilli JA. 2009. Identification of catalytic metal ion ligands in ribozymes. Methods 49: 148-166.

Ganguly A, Bevilacqua PC, Hammes-Schiffer S. 2011. Quantum mechanical/molecular mechanical study of the HDV Ribozyme: impact of the catalytic metal ion on the mechanism. J Phys Chem Lett 2: 2906-2911.

Ganguly A, Thaplyal P, Rosta E, Bevilacqua PC, Hammes-Schiffer S. 2014. Quantum mechanical/molecular mechanical free energy simulations of the self-cleavage reaction in the hepatitis delta virus ribozyme. J Am Chem Soc 136: 1483-1496.

Genheden S, Luchko T, Gusarov S, Kovalenko A, Ryde U. 2010. An MM/3D-RISM approach for ligand binding affinities. J Phys Chem B 114: 8505-8516.

Giambasu GM, Luchko T, Herschlag D, York DM, Case DA. 2014. Ion counting from explicit-solvent simulations and 3D-RISM. Biophys J 106: $883-894$.

Golden BL. 2011. Two distinct catalytic strategies in the hepatitis delta virus ribozyme cleavage reaction. Biochemistry 50: 9424-9433.

Golden BL, Hammes-Schiffer S, Carey PR, Bevilacqua PC. 2013. An integrated picture of HDV ribozyme catalysis. In Biophysics of RNA folding (ed. Russell R), pp. 135-167. Springer, New York.

Gong B, Chen J-H, Chase E, Chadalavada DM, Yajima R, Golden BL, Bevilacqua PC, Carey PR. 2007. Direct measurement of a pK(a) near neutrality for the catalytic cytosine in the genomic HDV 
ribozyme using Raman crystallography. J Am Chem Soc 129: 13335-13342.

Gong B, Chen J-H, Bevilacqua PC, Golden BL, Carey PR. 2009. Competition between $\mathrm{Co}\left(\mathrm{NH}_{3}\right)_{6}{ }^{3+}$ and inner sphere $\mathrm{Mg}^{2+}$ ions in the HDV ribozyme. Biochemistry 48: 11961-11970.

Horn HW, Swope WC, Pitera JW, Madura JD, Dick TJ, Hura GL, HeadGordon T. 2004. Development of an improved four-site water model for biomolecular simulations: TIP4P-Ew. J Chem Phys 120: 9665-9678.

Jeoung YH, Kumar PK, Suh YA, Taira K, Nishikawa S. 1994. Identification of phosphate oxygens that are important for selfcleavage activity of the HDV ribozyme by phosphorothioate substitution interference analysis. Nucleic Acids Res 22: 3722-3727.

Joung IS, Cheatham TE III. 2008. Determination of alkali and halide monovalent ion parameters for use in explicitly solvated biomolecular simulations. J Phys Chem B 112: 9020-9041.

Joung IS, Luchko T, Case DA. 2013. Simple electrolyte solutions: comparison of DRISM and molecular dynamics results for alkali halide solutions. J Chem Phys 138: 044103.

Kapral GJ, Jain S, Noeske J, Doudna JA, Richardson DC, Richardson JS. 2014. New tools provide a second look at HDV ribozyme structure, dynamics and cleavage. Nucleic Acids Res 42: 12833-12846.

Kast SM, Kloss T. 2008. Closed-form expressions of the chemical potential for integral equation closures with certain bridge functions. $J$ Chem Phys 129: 236101.

Kath-Schorr S, Wilson TJ, Li N-S, Lu J, Piccirilli JA, Lilley DMJ. 2012. General acid-base catalysis mediated by nucleobases in the hairpin ribozyme. J Am Chem Soc 134: 16717-16724.

Ke A, Zhou K, Ding F, Cate JHD, Doudna JA. 2004. A conformational switch controls hepatitis delta virus ribozyme catalysis. Nature 429: 201-205.

Ke A, Ding F, Batchelor JD, Doudna JA. 2007. Structural roles of monovalent cations in the HDV ribozyme. Structure 15: 281-287.

Konecny R, Baker NA, McCammon JA. 2012. iAPBS: a programming interface to the Adaptive Poisson-Boltzmann Solver (APBS). Comput Sci Disc 5: 015005.

Kovalenko A, Hirata F. 1999. Self-consistent description of a metal-water interface by the Kohn-Sham density functional theory and the three-dimensional reference interaction site model. J Chem Phys 110: 10095-10112.

Kuo MY, Sharmeen L, Dinter-Gottlieb G, Taylor J. 1988. Characterization of self-cleaving RNA sequences on the genome and antigenome of human hepatitis delta virus. J Virol 62: 4439-4444.

Lai MMC. 1995. The molecular biology of hepatitis delta virus. Annu Rev Biochem 64: 259-286.

Leclerc F. 2010. Hammerhead ribozymes: true metal or nucleobase catalysis? Where is the catalytic power from? Molecules 15: 5389-5407.

Lee T-S, Silva-Lopez C, Martick M, Scott WG, York DM. 2007. Insight into the role of $\mathrm{Mg}^{2+}$ in hammerhead ribozyme catalysis from $\mathrm{x}$-ray crystallography and molecular dynamics simulation. J Chem Theory Comput 3: 325-327.

Lee T-S, Giambasu GM, Sosa CP, Martick M, Scott WG, York DM. 2009. Threshold occupancy and specific cation binding modes in the hammerhead ribozyme active site are required for active conformation. J Mol Biol 388: 195-206.

Lee T-S, Giambasu GM, Harris ME, York DM. 2011. Characterization of the structure and dynamics of the HDV ribozyme in different stages along the reaction path. J Phys Chem Lett 2: 2538-2543.

Lee T-S, Radak BK, Huang M, Wong K-Y, York DM. 2014. Roadmaps through free energy landscapes calculated using the multidimensional vFEP approach. J Chem Theory Comput 10: 24-34.

Lévesque D, Reymond C, Perreault J-P. 2012. Characterization of the trans Watson-Crick GU base pair located in the catalytic core of the antigenomic HDV ribozyme. PLoS One 7: 40309.

Luchko T, Gusarov S, Roe DR, Simmerling C, Case DA, Tuszynski J, Kovalenko A. 2010. Three-dimensional molecular theory of solvation coupled with molecular dynamics in AMBER. J Chem Theory Comput 6: 607-624.
Lupták A, Ferré-D’Amaré AR, Zhou K, Zilm KW, Doudna JA. 2001. Direct $\mathrm{pK}(\mathrm{a})$ measurement of the active-site cytosine in a genomic hepatitis delta virus ribozyme. J Am Chem Soc 123: 8447-8452.

Mayaan E, Range K, York DM. 2004. Structure and binding of $\mathrm{Mg}$ (II) ions and di-metal bridge complexes with biological phosphates and phosphoranes. J Biol Inorg Chem 9: 807-817.

Misra VK, Draper DE. 2001. A thermodynamic framework for $\mathrm{Mg}^{2+}$ binding to RNA. Proc Natl Acad Sci 98: 12456-12461.

Nakano S, Bevilacqua PC. 2007. Mechanistic characterization of the HDV genomic ribozyme: a mutant of the $\mathrm{C} 41$ motif provides insight into the positioning and thermodynamic linkage of metal ions and protons. Biochemistry 46: 3001-3012.

Nakano S, Chadalavada DM, Bevilacqua PC. 2000. General acid-base catalysis in the mechanism of a hepatitis delta virus ribozyme. Science 287: 1493-1497.

Nakano S, Proctor DJ, Bevilacqua PC. 2001. Mechanistic characterization of the HDV genomic ribozyme: assessing the catalytic and structural contributions of divalent metal ions within a multichannel reaction mechanism. Biochemistry 40: 12022-12038.

Nakano S, Cerrone AL, Bevilacqua PC. 2003. Mechanistic characterization of the HDV genomic ribozyme: classifying the catalytic and structural metal ion sites within a multichannel reaction mechanism. Biochemistry 42: 2982-2994.

Nam K, Cui Q, Gao J, York DM. 2007. Specific reaction parametrization of the AM1/d Hamiltonian for phosphoryl transfer reactions: $\mathrm{H}, \mathrm{O}$, and P atoms. J Chem Theory Comput 3: 486-504.

Oyelere AK, Kardon JR, Strobel SA. 2002. pK(a) perturbation in genomic hepatitis delta virus ribozyme catalysis evidenced by nucleotide analogue interference mapping. Biochemistry 41: 3667-3675.

Panteva MT, Dissanayake T, Chen H, Radak BK, Kuechler ER, Giambasu GM, Lee T-S, York DM. 2015. Multiscale methods for computational RNA enzymology. In Methods in Enzymology (ed. Chen S-J, Burke-Aguero DH), Vol. 553, pp. 335-374. Elsevier, NY.

Pérez A, Marchán I, Svozil D, Sponer J, Cheatham TE III, Laughton CA, Orozco M. 2007. Refinement of the AMBER force field for nucleic acids: improving the description of $\alpha / \gamma$ conformers. Biophys $J$ 92: 3817-3829.

Perkyns JS, Pettitt BM. 1992. A dielectrically consistent interaction site theory for solvent-electrolyte mixtures. Chem Phys Lett 190: 626-630.

Perrotta AT, Been MD. 2006. HDV ribozyme activity in monovalent cations. Biochemistry 45: 11357-11365.

Perrotta AT, Shih I, Been MD. 1999. Imidazole rescue of a cytosine mutation in a self-cleaving ribozyme. Science 286: 123-126.

Perrotta AT, Wadkins TS, Been MD. 2006. Chemical rescue, multiple ionizable groups, and general acid-base catalysis in the HDV genomic ribozyme. RNA 12: 1282-1291.

Prabhu NS, Dinter-Gottlieb G, Gottlieb PA. 1997. Single substitutions of phosphorothioates in the HDV ribozyme G73 define regions necessary for optimal self-cleaving activity. Nucleic Acids Res 25: 5119-5124.

Radak BK, Harris ME, York DM. 2013a. Molecular simulations of RNA 2'-O-transesterification reaction models in solution. J Phys Chem B 117: 94-103.

Radak BK, Romanus M, Gallicchio E, Lee T-S, Weidner O, Deng N-J, He P, Dai W, York DM, Levy RM, et al. 2013b. A framework for flexible and scalable replica-exchange on production distributed CI. In Proceedings of the conference on extreme science and engineering discovery environment: gateway to discovery (XSEDE '13), pp. 26:1-26:8, Association for Computing Machinery (ACM), NY.

Raines K, Gottlieb PA. 1998. Enzymatic incorporation of 2'-thio-CTP into the HDV ribozyme. RNA 4: 340-345.

Roe DR, Cheatham TE III. 2013. PTRAJ and CPPTRAJ: software for processing and analysis of molecular dynamics trajectory data. $J$ Chem Theory Comput 9: 3084-3095.

Rosenstein SP, Been MD. 1990. Self-cleavage of hepatitis delta virus genomic strand RNA is enhanced under partially denaturing conditions. Biochemistry 29: 8011-8016. 
Salehi-Ashtiani K, Lupták A, Litovchick A, Szostak JW. 2006. A genomewide search for ribozymes reveals an HDV-like sequence in the human CPEB3 gene. Science 313: 1788-1792.

Salomon-Ferrer R, Götz AW, Poole D, Le Grand S, Walker RC. 2013. Routine microsecond molecular dynamics simulations with AMBER on GPUs. 2. Explicit solvent Particle Mesh Ewald. J Chem Theory Comput 9: 3878-3888.

Schnabl J, Sigel RKO. 2010. Controlling ribozyme activity by metal ions. Curr Opin Chem Biol 14: 269-275.

Sharmeen L, Kuo MY, Dinter-Gottlieb G, Taylor J. 1988. Antigenomic RNA of human hepatitis delta virus can undergo self-cleavage. J Virol 62: 2674-2679.

Shih I, Been MD. 2001. Involvement of a cytosine side chain in proton transfer in the rate-determining step of ribozyme self-cleavage. Proc Natl Acad Sci 98: 1489-1494.

Shirts MR, Chodera JD. 2008. Statistically optimal analysis of samples from multiple equilibrium states. J Chem Phys 129: 124105.

Sripathi KN, Tay WW, Banás P, Otyepka M, Šponer J, Walter NG. 2014. Disparate HDV ribozyme crystal structures represent intermediates on a rugged free-energy landscape. RNA 20: 1112-1128.

Suh YA, Kumar PK, Taira K, Nishikawa S. 1993. Self-cleavage activity of the genomic HDV ribozyme in the presence of various divalent metal ions. Nucleic Acids Res 21: 3277-3280.

Suydam IT, Levandoski SD, Strobel SA. 2010. Catalytic importance of a protonated adenosine in the hairpin ribozyme active site. Biochemistry 49: 3723-3732.

Thaplyal P, Ganguly A, Golden BL, Hammes-Schiffer S, Bevilacqua PC. 2013. Thio effects and an unconventional metal ion rescue in the genomic hepatitis delta virus ribozyme. Biochemistry 52: 6499-6514.

Thaplyal P, Ganguly A, Hammes-Schiffer S, Bevilacqua PC. 2015. Inverse thio effects in the hepatitis delta virus ribozyme reveal that the reaction pathway is controlled by metal ion charge density. Biochemistry 54: 2160-2175.

Thill G, Vasseur M, Tanner NK. 1993. Structural and sequence elements required for the self-cleaving activity of the hepatitis delta virus ribozyme. Biochemistry 32: 4254-4262.
Truchon J-F, Pettitt BM, Labute P. 2014. A cavity corrected 3D-RISM functional for accurate solvation free energies. J Chem Theory Comput 10: 934-941.

Veeraraghavan N, Ganguly A, Chen J-H, Bevilacqua PC, HammesSchiffer S, Golden BL. 2011a. Metal binding motif in the active site of the HDV ribozyme binds divalent and monovalent ions. Biochemistry 50: 2672-2682.

Veeraraghavan N, Ganguly A, Golden BL, Bevilacqua PC, HammesSchiffer S. 2011b. Mechanistic strategies in the HDV ribozyme: chelated and diffuse metal ion interactions and active site protonation. $J$ Phys Chem B 115: 8346-8357.

Walker RC, Crowley MF, Case DA. 2008. The implementation of a fast and accurate QM/MM potential method in Amber. J Comput Chem 29: 1019-1031.

Wang J, Cieplak P, Kollman PA. 2000. How well does a restrained electrostatic potential (RESP) model perform in calculating conformational energies of organic biological molecules. J Comput Chem 21: 1049-1074.

Ward WL, Plakos K, DeRose VJ. 2014. Nucleic acid catalysis: metals, nucleobases, and other cofactors. Chem Rev 114: 4318-4342.

Webb C-HT, Lupták A. 2011. HDV-like self-cleaving ribozymes. RNA Biol 8: 719-727.

Webb C-HT, Riccitelli NJ, Ruminski DJ, Lupták A. 2009. Widespread occurrence of self-cleaving ribozymes. Science 326: 953.

Wong GCL, Pollack L. 2010. Electrostatics of strongly charged biological polymers: ion-mediated interactions and self-organization in nucleic acids and proteins. Annu Rev Phys Chem 61: 171-189.

Wu H-N, Lin Y-J, Lin F-P, Makino S, Chang M-F. 1989. Human hepatitis dẹlta virus RNA subfragments contain an autocleavage activity. Proc Natl Acad Sci 86: 1831-1835.

Ye J-D, Li N-S, Dai Q, Piccirilli JA. 2007. The mechanism of RNA strand scission: an experimental measure of the Brønsted coefficient, $\beta_{\text {nuc }}$. Angew Chem Int Ed 119: 3788-3791.

Zgarbová M, Otyepka M, Šponer J, Mládek A, Banáš P, Cheatham TE III, Jurecka P. 2011. Refinement of the Cornell et al. nucleic acids force field based on reference quantum chemical calculations of glycosidic torsion profiles. J Chem Theory Comput 7: 2886-2902. 

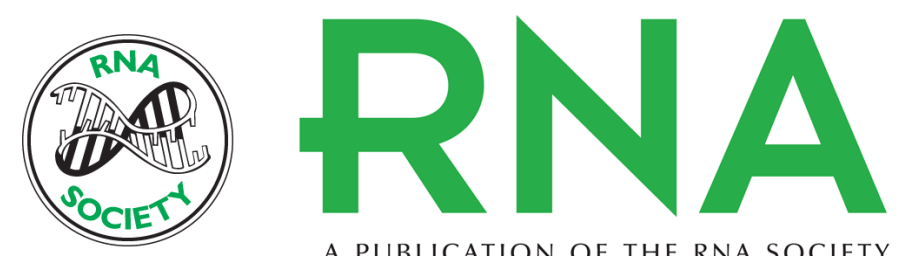

A PUBLICATION OF THE RNA SOCIETY

\section{Assessment of metal-assisted nucleophile activation in the hepatitis delta virus ribozyme from molecular simulation and 3D-RISM}

Brian K. Radak, Tai-Sung Lee, Michael E. Harris, et al.

RNA 2015 21: 1566-1577 originally published online July 13, 2015

Access the most recent version at doi:10.1261/rna.051466.115

References This article cites 84 articles, 14 of which can be accessed free at: http://rnajournal.cshlp.org/content/21/9/1566.full.html\#ref-list-1

Open Access Freely available online through the RNA Open Access option.

Creative This article, published in RNA, is available under a Creative Commons License

Commons (Attribution 4.0 International), as described at

License http://creativecommons.org/licenses/by/4.0/.

Email Alerting Receive free email alerts when new articles cite this article - sign up in the box at the Service top right corner of the article or click here.

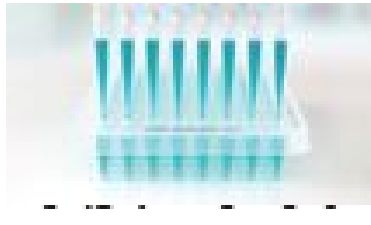

Providing Precise Solutions for your research.

To subscribe to RNA go to:

http://rnajournal.cshlp.org/subscriptions

(C) 2015 Radak et al.; Published by Cold Spring Harbor Laboratory Press for the RNA Society 